\title{
Moving fluid biomarkers for Alzheimer's disease from research tools to routine clinical diagnostics
}

\author{
Henrik Zetterberg ${ }^{1,2,3,4^{*}}$ and Kaj Blennow ${ }^{1,2^{*}}$
}

\begin{abstract}
Four fluid-based biomarkers have been developed into diagnostic tests for Alzheimer's disease (AD) pathology: the ratio of 42 to 40 amino acid-long amyloid $\beta$, a marker of plaque pathology; total-tau and phosphorylated tau, markers of AD-related changes in tau metabolism and secretion; and neurofilament light, a marker of neurodegeneration. When measured in cerebrospinal fluid, these biomarkers can be used in clinical practice to support a diagnosis of mild cognitive impairment or dementia due to AD. Recently, technological breakthroughs have made it possible to measure them in standard blood samples as well. Here, we give an updated account of the current state of the fluid-based AD biomarker research field. We discuss how the new blood tests may be used in research and clinical practice, and what role they may play in relation to more established diagnostic tests, such as CSF biomarkers and amyloid and tau positron emission tomography, to facilitate the effective implementation of future disease-modifying therapies.
\end{abstract}

Keywords: CSF, Plasma, Biomarkers, Alzheimer's disease, Research, Clinical diagnostics

\section{Background}

Alzheimer's disease (AD) is a slowly progressive neurodegenerative disease that currently lacks effective treatment. The first detectable pathology of the disease is the accumulation of 42 amino acid-long amyloid $\beta(\mathrm{A} \beta)$ protein in extracellular plaques in the brain, which occurs decades before clinical symptom onset [1]. Biomarker studies suggest that $A \beta$ accumulation is followed by increased phosphorylation and secretion of tau [2], a microtubule-binding axonal protein that is highly expressed in cortical neurons [3]. This dysfunctional tau metabolism is strongly associated with neuronal degeneration with the development of intraneuronal neurofibrillary tangles that are composed of hyperphosphorylated

\footnotetext{
*Correspondence: henrik.zetterberg@clinchem.gu.se;

kaj.blennow@neuro.gu.se

'Department of Psychiatry and Neurochemistry, Institute of Neuroscience \&

Physiology, Sahlgrenska Academy, University of Gothenburg, Mölndal, Sweden

Full list of author information is available at the end of the article
}

and truncated tau proteins [4]. Neurodegeneration eventually translates into the $\mathrm{AD}$ clinical syndrome, with cognitive symptoms that worsen as the disease progresses [5]. Four fluid-based biomarkers have been developed into diagnostic tests for these essential brain changes in the $\mathrm{AD}$ process: the ratio of 42 to 40 amino acid-long amyloid $\beta$ peptides (A $\beta 42 / A \beta 40)$, a marker of plaque pathology; total-tau and phosphorylated tau ( $\mathrm{T}$ tau and P-tau, respectively), markers of $\mathrm{AD}$-related changes in tau metabolism, phosphorylation and secretion; and neurofilament light (NfL), a marker of neurodegeneration [6]. Originally, these biomarkers could only be measured in cerebrospinal fluid (CSF), but technological progress resulting in improved analytical sensitivity has now made it possible to measure them in standard blood samples as well.

Here, we provide an overview of the biomarkers that reflect the core components of $\mathrm{AD}$ pathology, including biomarkers for $A \beta$ and tau pathology and neurodegeneration, 
in line with the amyloid (A), tau (T) and neurodegeneration $(\mathrm{N})$ classification scheme for AD biomarkers [7]. We describe the work that led to clinical implementation of the CSF biomarkers. We also provide a timeline for recent biomarker developments aimed at developing clinically implementable and easy-to-use blood tests for AD (Fig. 1). Finally, the most important biomarker measurement technologies for the $\mathrm{AD}$ biomarkers are summarized in Table 1.

\section{Fluid biomarkers for $A \beta$ pathology}

Extracellular deposition of $A \beta$ into plaques is the key pathological feature of $\mathrm{AD}$, and has been proposed as a major pathogenic event in the disease [8]. The development of tools to measure $A \beta$ pathology in vivo and prior to autopsy via biomarkers in CSF started in the 1990s [9], but it was not until 2020 that full standardization of CSF A $\beta 42$ measurement was achieved, through the use of certified reference materials and methods [10].

$\mathrm{AD}$ CSF is characterized by a $50 \%$ reduction in the concentration of the 42 amino acid-long and aggregation-prone form of $A \beta(A \beta 42)$ [11]. $A \beta 42$ is a secreted cleavage product of amyloid precursor protein (APP) that normally is mobilized from the brain interstitial fluid into the CSF and blood, likely via the glymphatic system [12]. In $A D, A \beta 42$ aggregates in the brain parenchyma, resulting in reduced CSF levels of the protein [13]. The diagnostic accuracy for $A \beta$ pathology can be increased by dividing the concentration of aggregation-prone $A \beta 42$ by the concentration of soluble A $\beta 40$ as a normalizer for inter-individual differences in $A \beta$ production [14]. The CSF $A \beta 42 / A \beta 40$ ratio is close to $100 \%$ concordant with amyloid positron emission tomography (PET), irrespective of which PET ligand that is used [14], and discordant subjects, who are typically CSF-positive and PET-negative, often turn PET-positive within a few years [14-16].

For many years, there was not much hope for a reliable blood test for cerebral $A \beta$ pathology [11], but recent findings suggest that plasma $A \beta 42$ in ratio with $A \beta 40$ (measured by immunoprecipitation mass spectrometry or ultrasensitive enzyme-linked immunosorbent assays) reflects cerebral $\mathrm{A} \beta$ pathology with relatively high accuracy against both amyloid PET and CSF A $\beta 42 / A \beta 40$ ratio [17-20]. A recent validation study utilizing a fully automated immunoassay (Elecsys) to measure plasma $A \beta 42$ and $A \beta 40$ further underscores the promising capability of plasma $A \beta$ in clinical laboratory practice [21]. Easyto-use protocols for pre-analytical sample handling, compatible across all plasma biomarkers for $\mathrm{AD}$, have also been published [22].

While the technological developments described above have been important for showing high diagnostic performance of plasma $A \beta$ to identify $A D$ and brain amyloidosis, a contributing factor is likely that most new studies have used amyloid PET as the reference standard. This reduces the risk of evaluating the diagnostic performance on amyloid-negative "probable $\mathrm{AD}$ " patients versus cognitively unimpaired elderly who may have pre-symptomatic $A \beta$ pathology. Having a

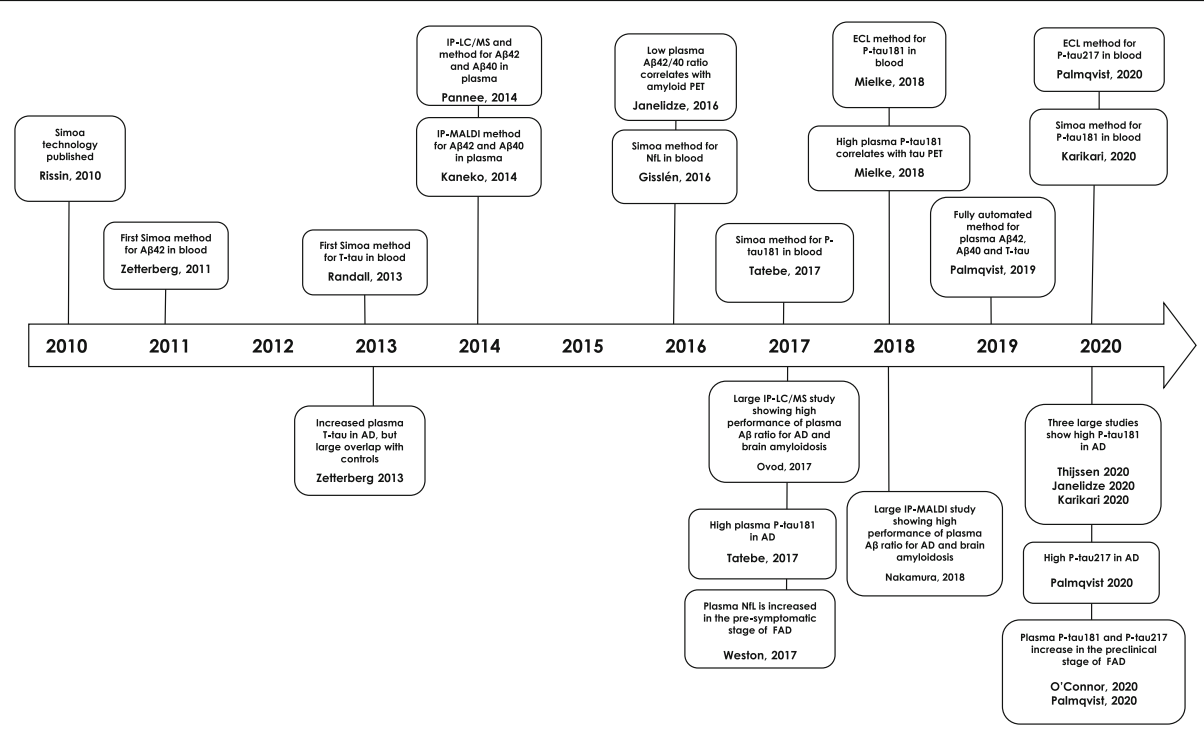

Fig. 1 Timeline for blood biomarker developments during the last decade. Abbreviations: Simoa, Single molecule array; A 42 , the 42 amino acid form of amyloid $\beta$; T-tau, total-tau; IP-LC/MS, immunoprecipitation liquid chromatography-mass spectrometry; IP-MALDI, immunoprecipitation matrix-assisted laser desorption/ionization; A 440 , the 40 amino acid form of amyloid $\beta$; NfL, neurofilament light; P-tau181, tau phosphorylated at amino acid 181; P-tau217, tau phosphorylated at amino acid 217; ECL, electrochemiluminescence 
Table 1 General description of the most important measurement technologies for Alzheimer's disease biofluid-based biomarkers

\begin{tabular}{|c|c|}
\hline Technology & Explanation \\
\hline $\begin{array}{l}\text { Sandwich enzyme-linked immunosorbent } \\
\text { assay (ELISA) }\end{array}$ & $\begin{array}{l}\text { The target analyte is captured between two antibodies (capture and detection). The capture antibody } \\
\text { is immobilized onto a surface (often the plastic surface of a well, e.g., in a } 96 \text {-well plate). The detection } \\
\text { antibody is labeled with an enzyme that produces a measurable signal (fluorescence or color) by } \\
\text { converting a substrate to a product. The lower limit of quantification of an ELISA depends on the } \\
\text { antibodies and the target analyte but is often in the nano- to picomolar range. }\end{array}$ \\
\hline $\begin{array}{l}\text { Immunoassay with } \\
\text { electrochemiluminescence detection (ECL) }\end{array}$ & $\begin{array}{l}\text { A variant of ELISA but instead of an enzyme, the detection antibody is labeled with a molecule } \\
\text { that directly produces luminescence during an electrochemical reaction. This detection principle } \\
\text { is often a little bit more sensitive than ELISA. }\end{array}$ \\
\hline Single molecule array (Simoa) & $\begin{array}{l}\text { This is a classical sandwich ELISA, but the capture antibody is conjugated to magnetic beads instead } \\
\text { of the bottom of a 96-well plate, and the sandwich complexes (bead, capture antibody, target analyte } \\
\text { and enzyme-labeled detection antibody) are pulled down in microwells (one bead per well), where the } \\
\text { detection reaction is allowed to occur. This compartmentalized detection reaction in a very small volume } \\
\text { allows for the detection of the biomarker at the single molecule level. In biofluids, the Simoa assays can } \\
\text { be } 100 \text { to } 1000 \text { times as sensitive as a regular ELISA (subfemtomolar analytical sensitivity). }\end{array}$ \\
\hline $\begin{array}{l}\text { Immunoprecipitation mass spectrometry } \\
\text { (IP-MS) }\end{array}$ & $\begin{array}{l}\text { This technology has been particularly useful for the development of reliable plasma amyloid } \beta \text { tests. } \\
\text { Antibodies against the target analyte are conjugated to beads, and the target analyte is isolated from } \\
\text { the sample by immunoprecipitation, eluted, and then quantified by mass spectrometry, together with } \\
\text { an isotope-labeled internal standard. The mass spectrometric detection makes the assay very specific } \\
\text { for the target analyte. }\end{array}$ \\
\hline
\end{tabular}

proportion of misdiagnosed cases and controls will markedly reduce the chance to find differences in plasma $A \beta$, given that the $A \beta 42 / A \beta 40$ ratio is reduced by only $14-20 \%$ in plasma [17-20], compared with $50 \%$ in CSF [11]. A complicating factor for plasma A $\beta$ tests is also that the correlation between plasma and CSF levels is weak, which could be explained by production of $A \beta$ peptides in platelets and other non-cerebral tissues. Nevertheless, the concordant research findings using high-precision analytical tools still represent an important research advancement towards clinical implementation, perhaps using staged testing (e.g., an $A \beta$ test in blood favoring sensitivity over specificity, followed by a more specific CSF- or imaging-based test in memory clinics).

\section{Biomarkers for tau pathology}

The aggregation of hyperphosphorylated forms of the axonal protein tau in the neuronal soma, forming neurofibrillary tangles, is a key pathological feature of AD, although tau inclusions in neurons or glial cells are also found in some non-AD neurodegenerative dementias, e.g., progressive supranuclear palsy and some forms of frontotemporal dementia [23]. Together with the A $\beta 42 /$ $\mathrm{A} \beta 40$ ratio, CSF $\mathrm{T}$-tau and $\mathrm{P}$-tau have been proposed as biomarkers to biologically define AD [24], and are considered diagnostic in the research criteria for AD [25]. Both CSF T-tau and P-tau concentrations reflect ADrelated pathophysiology, but do not reflect tau pathology in non-AD tauopathies [26, 27]. The most likely explanation for this is that the increased CSF levels of tau are due to increased phosphorylation and secretion of tau from neurons, as a neuronal response to $A \beta$ exposure $[28,29]$. In the non-AD tauopathies, tau aggregation appears to occur in neurons, and sometimes other cell types as well, without this being reflected in the extracellular fluid, at least not when the currently available Ttau and P-tau assays are used. CSF T-tau and P-tau may thus be regarded predictive markers of AD-type neurodegeneration and tangle formation, but not direct markers of these processes (and not markers of non-AD tauopathies, for which improved biomarkers are needed). However, CSF T-tau also increases in disorders with rapid neurodegeneration without amyloid or tau pathology, specifically in Creutzfeldt-Jakob disease [30] and in acute conditions such as stroke and brain trauma [31, 32], suggesting that it also may reflect neuronal injury in these conditions. Fully automated T-tau and P-tau assays for clinical use are available [33, 34], and standardization work is ongoing in collaborative efforts between the International Federation of Clinical Chemistry and Laboratory Medicine (IFCC) and the Global Biomarker Standardization Consortium (GBSC).

Regarding which phospho-form of tau to measure, the three main competitors are P-tau181, P-tau217 and Ptau231. P-tau181 is the classical AD biomarker, whilst Ptau231 was suggested to improve the differentiation of AD from frontotemporal dementia [35]; they now seem to perform similarly well in this regard. Recent data suggest that CSF P-tau217 may correlate more strongly with tau pathology determined by PET and increase earlier in response to $A \beta$ pathology than CSF P-tau181 [36], intriguing observations that warrant additional research.

Whilst ultrasensitive plasma T-tau assays can detect neuronal injury in acute brain disorders, such as stroke and traumatic brain injury $[37,38]$, similarly to when Ttau is measured in CSF (see above), they work relatively poorly in AD settings [39], and the correlation with CSF is weak [40]. A potential explanation for this is that the assay set up may be vulnerable to proteolytic 
degradation of tau in the blood (the half-life of tau measured using currently available T-tau assays is 10 hours [41], compared with around 20 days in CSF [29]; detection of small tau fragments resistant to further proteolytic degradation may be a viable way forward towards a reliable tau assay in blood). Another possibility is that currently available T-tau assays in blood may measure peripheral tau; measuring a phospho-form of tau might make the test more CNS-specific.

Recently, we have seen a number of real breakthroughs in the plasma tau biomarker field. In 2017, Tatebe et al.. reported on the quantification of P-tau181 concentration in AD plasma with increased levels compared with control samples for which most had concentrations below the lower limit of quantification, and a good correlation between plasma and CSF P-tau levels [42]. Mielke et al.. used an immunoassay with electrochemiluminescence (ECL) detection and demonstrated a correlation between P-tau181, and amyloid and tau PET, which indicates that plasma P-tau181 is a good biomarker for brain $\mathrm{AD}$ pathology [43]. Using the same ECL immunoassay, these findings were replicated in a study by Palmqvist et al.., demonstrating that plasma Ptau181 associates with amyloid PET positivity and correlates strongly with CSF P-tau181 [2]. Interestingly, the change in plasma P-tau181 became significant before amyloid PET, but after CSF and plasma $A \beta 42$, i.e., already at sub-PET threshold $A \beta$ pathology [2]. Thus, plasma P-tau181 might be useful both diagnostically to detect early A $\beta$-related tau dysmetabolism, as well as for disease staging. Recent large validation studies show very similar results [44-47], corroborating plasma P-tau as a robust blood biomarker for AD pathology that should be relatively easy to standardize and implement in clinical laboratory practice.

Most data currently available suggest that P-tau217 is earlier and more strongly associated with AD pathology than plasma P-tau181 [47, 48], but more head-to-head comparisons are needed before a conclusion can be reached. As an example, while plasma P-tau217 measured by the ECL immunoassay showed an AUC of 0.89 to differentiate neuropathologically defined $\mathrm{AD}$ from non-AD in blood samples taken during life in one cohort [47], the corresponding number for plasma Ptau181 measured using Single molecule array (Simoa ${ }^{\mathrm{Tm}}$ ) was 0.97 in another [49]. These findings call for further studies comparing different P-tau biomarkers in the same cohort. Interestingly, high plasma P-tau181 is found in tau PET-negative (Braak stage 0) individuals who have evidence of brain amyloidosis by amyloid PET [46], predicts subsequent $\mathrm{AD}$ dementia in cognitively unimpaired individuals and MCI patients [45], and plasma P-tau181 levels show a significant increase in pre-symptomatic familial $\mathrm{AD}$ mutation carriers 16 years before estimated symptom onset [50]. Collectively, these data suggest that plasma P-tau181 detects $A \beta$-induced tau pathophysiology years before tau pathology is detectable by PET.

\section{Fluid biomarkers for neurodegeneration}

Whilst CSF $\mathrm{T}$-tau might better reflect $\mathrm{A} \beta$-induced tau secretion in $\mathrm{AD}$ rather than general neurodegeneration [39], neurofilament light (NfL) has emerged as a strong biomarker candidate for the latter [51]. The biomarker can be measured in both CSF and plasma (or serum), and the correlation between CSF and blood concentrations is good to excellent ( $r$ values of 0.70 to 0.97 ) [52]. The highest NfL levels are seen in frontotemporal, as well as vascular and HIV-associated dementias [53]. However, the findings in familial AD are also quite clear; mutation carriers show a sudden change in their blood NfL levels 10-15 years before expected clinical onset, which probably marks the onset and intensity of the neurodegenerative process $[54,55]$. In sporadic $\mathrm{AD}$, there is a clear association of increased plasma NfL concentration with $A \beta$ and tau PET positivity, as well as with longitudinal neurodegeneration as determined by magnetic resonance imaging (MRI), but with a larger overlap across groups than in familial AD [56]. This might be due to the multitude of neurodegenerative changes that may cause NfL increase in people older than 70 years of age.

\section{From research tools to clinical implementation}

In Europe, CSF biomarkers as supportive tools in the diagnostic evaluation of patients with suspected AD have been used in memory clinics since the early 2000s, but they have not yet been formally approved or recommended by regulatory authorities. Both the European Medical Agency (EMA) and the United States Food and Drug Administration (FDA) have encouraged the further study of CSF biomarkers in the context of clinical AD diagnostics, and the Coalition Against Major Diseases (CAMD) CSF Biomarker Team is working toward seeking formal qualification from the FDA on the use of CSF biomarkers for clinical trial enrichment at the predementia stage of the disease [57]. Additionally, the Alzheimer's Association has published Appropriate Use Criteria, i.e., specific clinical indications when the CSF tests are warranted in the diagnostic assessment of patients with suspected AD [58]. Standard operating procedures for pre-analytical sample handling have been agreed upon and published for both CSF [59] and plasma [22]. Reference methods and materials for CSF A $\beta 42$ assay standardization [10], as well as high-precision clinical chemistry tests on fully automated instruments, are in place [60], which bodes well for full implementation of these biomarkers in clinical laboratory practice with 
uniform reference limits around the globe; in many European countries CSF biomarkers are already used in clinical laboratory practice in accordance with countryspecific regulations. Work on the reference measurement procedures for CSF A $\beta 40, T$-tau and P-tau181 is ongoing under the auspices of the IFCC CSF Proteins working group; the $A \beta 40$ part of this work should be concluded during 2020. Similar work is now also being initiated for the blood tests. Plasma NfL is already an available test in clinical laboratory practice in Sweden, the Netherlands and France, and many clinical laboratories are now working towards validating plasma P-tau tests for clinical use.

\section{Limitations of fluid-based biomarkers}

A drawback of fluid biomarkers is the inability to determine brain region-specific changes, which may limit staging of disease severity and their use as progression markers. For plasma P-tau181, a step-wise increase with disease severity has been reported [46], and similar data have been reported for plasma NfL (with the caveat that this biomarker is not specific to AD progression) [56], but this is less clear for the other biomarkers; the CSF A $442 / A \beta 40$ ratio, for example, appears to be a bimodal marker (normal or abnormal) without a clear relationship between the degree of change and the extent of the pathology [14]. Tau and A $\beta$ PET imaging may be done to provide a more direct assessment of disease stage in select clinical cases and in clinical trials.

\section{Conclusions}

We may see a regulatory approval of an $A \beta$-targeting drug in the near future. This class of treatments will likely be expensive and there will be a need to ensure that patients who are considered for the treatment actually do have the drug target. Synthesizing the recent biomarker breakthroughs above, it is relatively easy to envision blood-based testing for $\mathrm{AD}$ pathology using plasma $A \beta 42 / A \beta 40$ ratio and plasma P-tau as screening tools. Positive patients could then be referred to a specialized memory clinic to be more closely examined, undergo amyloid PET imaging where available, and commence treatment with an anti-A $\beta$ antibody therapy, if $\mathrm{A} \beta$ positivity is verified. Plasma P-tau (representing a neuronal reaction to $A \beta$ ) and NfL levels (representing neurodegeneration) could be monitored throughout the treatment (e.g., every third month, given the dynamics of NfL change after acute brain injury [61]), followed by yearly amyloid PET scans (given the observed amyloid PET changes in anti-A $\beta$ clinical trials [62]). For anti-A $\beta$ antibodies, repeat MRIs would be needed, at least initially, to monitor amyloid-related imaging abnormalities (ARIA) [63], but in the future, it is possible that increases in plasma NfL concentration could substitute for MRI to detect clinically relevant ARIA (this potential use needs to be formally examined, though). The patient could then be treated until amyloid PET is negative and plasma P-tau concentration has normalized. Post-treatment, the patient could be followed with annual plasma P-tau and NfL measurements to gauge the potential need for additional therapy. In our view, future clinical trials should incorporate both imaging and fluid biomarker approaches to assess biological response, at the same time as they provide the information needed to develop the most effective biomarker algorithm for treatment selection, dose optimization and drug monitoring.

\section{Abbreviations \\ AD: Alzheimer's disease; A : Amyloid $\beta$; T-tau: Total-tau; P- tau: Phosphorylated tau; NfL: Neurofilament light; CSF: Cerebrospinal fluid; APP: Amyloid precursor protein; PET: Positron emission tomography; ECL: Electrochemiluminescence; Simoa: Single molecule array; MRI: Magnetic resonance imaging; CAMD: Coalition Against Major Diseases; EMA: European Medical Agency; IFCC: International Federation of Clinical Chemistry and Laboratory Medicine; ARIA: Amyloid-related imaging abnormalities}

\section{Acknowledgements}

Not applicable.

Authors' contributions

$\mathrm{HZ}$ and $\mathrm{KB}$ contributed equally to this work. Both authors wrote the paper. Both authors read and approved the final manuscript.

\section{Funding}

$\mathrm{HZ}$ is a Wallenberg Scholar supported by grants from the Swedish Research Council (\#2018-02532), the European Research Council (\#681712), Swedish State Support for Clinical Research (\#ALFGBG-720931), the Alzheimer Drug Discovery Foundation (ADDF), USA (\#201809-2016862), and the UK Dementia Research Institute at UCL. KB is supported by the Swedish Research Council (\#2017 - 00915), the Alzheimer Drug Discovery Foundation (ADDF), USA (\#RDAPB-201809-2016615), the Swedish Alzheimer Foundation (\#AF-742881), Hjärnfonden, Sweden (\#FO2017-0243), the Swedish state under the agreement between the Swedish government and the County Councils, the ALF-agreement (\#ALFGBG-715986), and European Union Joint Program for Neurodegenerative Disorders (JPND2019-466-236). Open Access funding provided by University of Gothenburg.

Availability of data and materials

Not applicable.

Ethical approval and consent to participate Not applicable.

\section{Consent for publication}

Not applicable.

\section{Competing interests}

$\mathrm{HZ}$ has served at scientific advisory boards for Denali, Roche Diagnostics, Wave, Samumed, Siemens Healthineers, Pinteon Therapeutics and CogRx, has given lectures in symposia sponsored by Fujirebio, Alzecure and Biogen, and is a co-founder of Brain Biomarker Solutions in Gothenburg AB (BBS), which is a part of the GU Ventures Incubator Program (outside submitted work). KB has served as a consultant, at advisory boards, or at data monitoring committees for Abcam, Axon, Biogen, Julius Clinical, Lilly, MagQu, Novartis, Roche Diagnostics, and Siemens Healthineers, and is a co-founder of Brain Biomarker Solutions in Gothenburg AB (BBS), which is a part of the GU Ventures Incubator Program (outside submitted work). 


\section{Author details}

Department of Psychiatry and Neurochemistry, Institute of Neuroscience \& Physiology, Sahlgrenska Academy, University of Gothenburg, Mölndal, Sweden. ${ }^{2}$ Clinical Neurochemistry Laboratory, Sahlgrenska University Hospital, Mölndal, Sweden. ${ }^{3}$ Department of Neurodegenerative Disease, UCL Institute of Neurology, Queen Square, London, UK. ${ }^{4}$ UK Dementia Research Institute at UCL, London, UK

\section{Received: 7 September 2020 Accepted: 5 February 2021}

\section{Published online: 19 February 2021}

\section{References}

1. DeTure MA, Dickson DW. The neuropathological diagnosis of Alzheimer's disease. Mol Neurodegener. 2019;14:32.

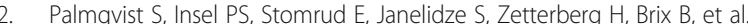
Cerebrospinal fluid and plasma biomarker trajectories with increasing amyloid deposition in Alzheimer's disease. EMBO Mol Med. 2019;11:e11170.

3. Kent SA, Spires-Jones TL, Durrant CS. The physiological roles of tau and Abeta: implications for Alzheimer's disease pathology and therapeutics. Acta Neuropathol. 2020

4. Jellinger KA. Neuropathological assessment of the Alzheimer spectrum. J Neural Transm (Vienna). 2020;127:1229-56.

5. Jack CR Jr, Holtzman DM. Biomarker modeling of Alzheimer's disease. Neuron. 2013:80:1347-58

6. Blennow K, Hampel H, Weiner M, Zetterberg H. Cerebrospinal fluid and plasma biomarkers in Alzheimer disease. Nat Rev Neurol. 2010;6:131-44

7. Jack CR Jr, Bennett DA, Blennow K, Carrillo MC, Feldman HH, Frisoni GB, et al. A/T/N: An unbiased descriptive classification scheme for Alzheimer disease biomarkers. Neurology. 2016;87:539-47.

8. Selkoe DJ, Hardy J. The amyloid hypothesis of Alzheimer's disease at 25 years. EMBO Mol Med. 2016:8:595-608.

9. Ashton NJ, Scholl M, Heurling K, Gkanatsiou E, Portelius E, Hoglund K, et al. Update on biomarkers for amyloid pathology in Alzheimer's disease. Biomark Med. 2018;12:799-812

10. Boulo S, Kuhlmann J, Andreasson U, Brix B, Venkataraman I, Herbst V, et al. First amyloid beta1-42 certified reference material for re-calibrating commercial immunoassays. Alzheimers Dement. 2020.

11. Olsson B, Lautner R, Andreasson U, Ohrfelt A, Portelius E, Bjerke M, et al. CSF and blood biomarkers for the diagnosis of Alzheimer's disease: a systematic review and meta-analysis. Lancet Neurol. 2016;15:673-84.

12. Rasmussen MK, Mestre $H$, Nedergaard M. The glymphatic pathway in neurological disorders. Lancet Neurol. 2018;17:1016-24.

13. Strozyk D, Blennow K, White LR, Launer LJ. CSF Abeta 42 levels correlate with amyloid-neuropathology in a population-based autopsy study. Neurology. 2003;60:652-6.

14. Hansson $\mathrm{O}$, Lehmann $\mathrm{S}$, Otto $\mathrm{M}$, Zetterberg $\mathrm{H}$, Lewczuk P. Advantages and disadvantages of the use of the CSF Amyloid beta (Abeta) 42/40 ratio in the diagnosis of Alzheimer's Disease. Alzheimers Res Ther. 2019:11:34.

15. Lewczuk P, Matzen A, Blennow K, Parnetti L, Molinuevo JL, Eusebi $P$, et al. Cerebrospinal Fluid Abeta42/40 Corresponds Better than Abeta42 to Amyloid PET in Alzheimer's Disease. J Alzheimers Dis. 2017;55:813-22.

16. Mattsson N, Palmqvist S, Stomrud E, Vogel J, Hansson O. Staging betaAmyloid Pathology With Amyloid Positron Emission Tomography. JAMA Neurol. 2019;76(11). doi:https://doi.org/10.1001/jamaneurol.2019.2214. Online ahead of print.

17. Janelidze S, Stomrud E, Palmqvist $S$, Zetterberg $H$, van Westen $D$, Jeromin A et al. Plasma beta-amyloid in Alzheimer's disease and vascular disease. Sci Rep. 2016;6:26801

18. Nakamura A, Kaneko N, Villemagne VL, Kato T, Doecke J, Dore V, et al. High performance plasma amyloid-beta biomarkers for Alzheimer's disease. Nature. 2018;554:249-54

19. Ovod V, Ramsey KN, Mawuenyega KG, Bollinger JG, Hicks T, Schneider T, et al. Amyloid beta concentrations and stable isotope labeling kinetics of human plasma specific to central nervous system amyloidosis. Alzheimers Dement. 2017;13:841-9.

20. Schindler SE, Bollinger JG, Ovod V, Mawuenyega KG, Li Y, Gordon BA, et al. High-precision plasma beta-amyloid $42 / 40$ predicts current and future brain amyloidosis. Neurology. 2019;93:e1647-e59.

21. Palmqvist S, Janelidze S, Stomrud E, Zetterberg H, Karl J, Zink K, et al. Performance of Fully Automated Plasma Assays as Screening Tests for Alzheimer Disease-Related beta-Amyloid Status. JAMA Neurol. 2019.
22. Rozga M, Bittner T, Batrla R, Karl J. Preanalytical sample handling recommendations for Alzheimer's disease plasma biomarkers. Alzheimers Dement (Amst). 2019;11:291-300.

23. Irwin DJ. Tauopathies as clinicopathological entities. Parkinsonism Relat Disord. 2016;22(Suppl 1):29-33.

24. Jack CR Jr, Bennett DA, Blennow K, Carrillo MC, Dunn B, Haeberlein SB, et al. NIA-AA Research Framework: Toward a biological definition of Alzheimer's disease. Alzheimers Dement. 2018;14:535-62.

25. Dubois B, Feldman HH, Jacova C, Hampel H, Molinuevo JL, Blennow K, et al Advancing research diagnostic criteria for Alzheimer's disease: the IWG-2 criteria. Lancet Neurol. 2014:13:614-29.

26. Itoh N, Arai H, Urakami K, Ishiguro K, Ohno H, Hampel H, et al. Large-scale, multicenter study of cerebrospinal fluid tau protein phosphorylated at serine 199 for the antemortem diagnosis of Alzheimer's disease. Ann Neurol. 2001:50:150-6.

27. Skillback T, Farahmand BY, Rosen C, Mattsson N, Nagga K, Kilander L, et al. Cerebrospinal fluid tau and amyloid-beta(1-42) in patients with dementia. Brain. 2015;138:2716-31.

28. Maia LF, Kaeser SA, Reichwald J, Hruscha M, Martus P, Staufenbiel M, et al. Changes in Amyloid-beta and Tau in the Cerebrospinal Fluid of Transgenic Mice Overexpressing Amyloid Precursor Protein. Sci Transl Med. 2013:5: 194 re2.

29. Sato C, Barthelemy NR, Mawuenyega KG, Patterson BW, Gordon BA, JockelBalsarotti J, et al. Tau Kinetics in Neurons and the Human Central Nervous System. Neuron. 2018;98:861-4

30. Skillback T, Rosen C, Asztely F, Mattsson N, Blennow K, Zetterberg H. Diagnostic performance of cerebrospinal fluid total tau and phosphorylated tau in Creutzfeldt-Jakob disease: results from the Swedish Mortality Registry. JAMA Neurol. 2014;71:476-83.

31. Hesse C, Rosengren L, Andreasen N, Davidsson P, Vanderstichele H, Vanmechelen E, et al. Transient increase in total tau but not phospho-tau in human cerebrospinal fluid after acute stroke. Neurosci Lett. 2001:297:187-90.

32. Ost M, Nylen K, Csajbok L, Ohrfelt AO, Tullberg M, Wikkelso C, et al. Initial CSF total tau correlates with 1-year outcome in patients with traumatic brain injury. Neurology. 2006;67:1600-4

33. Leitao MJ, Silva-Spinola A, Santana I, Olmedo V, Nadal A, Le Bastard N, et al. Clinical validation of the Lumipulse $G$ cerebrospinal fluid assays for routine diagnosis of Alzheimer's disease. Alzheimers Res Ther. 2019;11:91.

34. Blennow K, Shaw LM, Stomrud E, Mattsson N, Toledo JB, Buck K, et al. Predicting clinical decline and conversion to Alzheimer's disease or dementia using novel Elecsys Abeta(1-42), pTau and tTau CSF immunoassays. Sci Rep. 2019:9:19024.

35. Hampel H, Buerger K, Zinkowski R, Teipel SJ, Goernitz A, Andreasen N, et al. Measurement of phosphorylated tau epitopes in the differential diagnosis of Alzheimer disease: a comparative cerebrospinal fluid study. Arch Gen Psychiatry. 2004;61:95-102.

36. Janelidze S, Stomrud E, Smith R, Palmqvist S, Mattsson N, Airey DC, et al. Cerebrospinal fluid p-tau217 performs better than p-tau181 as a biomarker of Alzheimer's disease. Nat Commun. 2020:11:1683.

37. De Vos A, Bjerke M, Brouns R, De Roeck N, Jacobs D, Van den Abbeele L, et al. Neurogranin and tau in cerebrospinal fluid and plasma of patients with acute ischemic stroke. BMC Neurol. 2017;17:170.

38. Bogoslovsky T, Diaz-Arrastia R. Dissecting Temporal Profiles of Neuronal and Axonal Damage After Mild Traumatic Brain Injury. JAMA Neurol. 2016;73: 506-7.

39. Zetterberg H. Review. Tau in biofluids - relation to pathology, imaging and clinical features. Neuropathol Appl Neurobiol. 2017:43:194-9.

40. Pereira JB, Westman E, Hansson O. Alzheimer's Disease Neuroimaging I. Association between cerebrospinal fluid and plasma neurodegeneration biomarkers with brain atrophy in Alzheimer's disease. Neurobiol Aging. 2017;58:14-29.

41. Randall J, Mortberg E, Provuncher GK, Fournier DR, Duffy DC, Rubertsson S, et al. Tau proteins in serum predict neurological outcome after hypoxic brain injury from cardiac arrest: results of a pilot study. Resuscitation. 2013 84:351-6.

42. Tatebe H, Kasai T, Ohmichi T, Kishi Y, Kakeya T, Waragai M, et al. Quantification of plasma phosphorylated tau to use as a biomarker for brain Alzheimer pathology: pilot case-control studies including patients with Alzheimer's disease and down syndrome. Mol Neurodegener. 2017;12:63.

43. Mielke MM, Hagen CE, Xu J, Chai X Vemuri P, Lowe VJ, et al. Plasma phospho-tau181 increases with Alzheimer's disease clinical severity and is 
associated with tau- and amyloid-positron emission tomography. Alzheimers Dement. 2018;14:989-97.

44. Thijssen EH, La Joie R, Wolf A, Strom A, Wang P, laccarino L, et al. Diagnostic value of plasma phosphorylated tau181 in Alzheimer's disease and frontotemporal lobar degeneration. Nat Med. 2020;26:387-97.

45. Janelidze S, Mattsson N, Palmqvist S, Smith R, Beach TG, Serrano GE, et al. Plasma P-tau181 in Alzheimer's disease: relationship to other biomarkers, differential diagnosis, neuropathology and longitudinal progression to Alzheimer's dementia. Nat Med. 2020;26:379-86.

46. Karikari TK, Pascoal TA, Ashton NJ, Janelidze S, Benedet AL, Rodriguez JL, et al. Blood phosphorylated tau 181 as a biomarker for Alzheimer's disease: a diagnostic performance and prediction modelling study using data from four prospective cohorts. Lancet Neurol. 2020;19:422-33.

47. Palmqvist S, Janelidze S, Quiroz YT, Zetterberg H, Lopera F, Stomrud E, et al. Discriminative Accuracy of Plasma Phospho-tau217 for Alzheimer Disease vs Other Neurodegenerative Disorders. JAMA. 2020.

48. Barthelemy NR, Horie K, Sato C, Bateman RJ. Blood plasma phosphorylatedtau isoforms track CNS change in Alzheimer's disease. J Exp Med. 2020;217.

49. Lantero Rodriguez J, Karikari TK, Suarez-Calvet M, Troakes C, King A, Emersic A, et al. Plasma p-tau181 accurately predicts Alzheimer's disease pathology at least 8 years prior to post-mortem and improves the clinical characterisation of cognitive decline. Acta Neuropathol. 2020;140:267-78.

50. O'Connor A, Karikari TK, Poole T, Ashton NJ, Lantero Rodriguez J, Khatun A, et al. Plasma phospho-tau181 in presymptomatic and symptomatic familial Alzheimer's disease: a longitudinal cohort study. Mol Psychiatry. 2020.

51. Khalil M, Teunissen CE, Otto M, Piehl F, Sormani MP, Gattringer T, et al. Neurofilaments as biomarkers in neurological disorders. Nat Rev Neurol. 2018;14:577-89.

52. Gaetani L, Blennow K, Calabresi P, Di Filippo M, Parnetti L, Zetterberg H. Neurofilament light chain as a biomarker in neurological disorders. J Neurol Neurosurg Psychiatry. 2019;90:870-81.

53. Bridel $C$, van Wieringen WN, Zetterberg $H$, Tijms BM, Teunissen $C E$, and the NFLG, et al. Diagnostic Value of Cerebrospinal Fluid Neurofilament Light Protein in Neurology: A Systematic Review and Meta-analysis. JAMA Neurol. 2019.

54. Weston PSJ, Poole T, O'Connor A, Heslegrave A, Ryan NS, Liang Y, et al. Longitudinal measurement of serum neurofilament light in presymptomatic familial Alzheimer's disease. Alzheimers Res Ther. 2019;11:19.

55. Preische O, Schultz SA, Apel A, Kuhle J, Kaeser SA, Barro C, et al. Serum neurofilament dynamics predicts neurodegeneration and clinical progression in presymptomatic Alzheimer's disease. Nat Med. 2019;25:277-83.

56. Mattsson N, Cullen NC, Andreasson U, Zetterberg H, Blennow K. Association Between Longitudinal Plasma Neurofilament Light and Neurodegeneration in Patients With Alzheimer Disease. JAMA Neurol. 2019;76:791-9.

57. Arneric SP, Batrla-Utermann R, Beckett L, Bittner T, Blennow K, Carter $L$, et al. Cerebrospinal Fluid Biomarkers for Alzheimer's Disease: A View of the Regulatory Science Qualification Landscape from the Coalition Against Major Diseases CSF Biomarker Team. J Alzheimers Dis. 2017;55:19-35.

58. Shaw LM, Arias J, Blennow K, Galasko D, Molinuevo JL, Salloway S, et al. Appropriate use criteria for lumbar puncture and cerebrospinal fluid testing in the diagnosis of Alzheimer's disease. Alzheimers Dement. 2018;14:1505-21.

59. Spitzer P, Klafki HW, Blennow K, Buee L, Esselmann H, Herruka SK, et al. CNEUPRO: Novel Biomarkers for Neurodegenerative Diseases. Int J Alzheimers Dis. 2010;2010.

60. Kuhlmann J, Andreasson U, Pannee J, Bjerke M, Portelius E, Leinenbach A, et al. CSF Abeta1-42 - an excellent but complicated Alzheimer's biomarker a route to standardisation. Clin Chim Acta. 2017;467:27-33.

61. Bergman J, Dring A, Zetterberg H, Blennow K, Norgren N, Gilthorpe J, Bergenheim T, Svenningsson A. Neurofilament light in CSF and serum is a sensitive marker for axonal white matter injury in MS. Neurol Neuroimmunol Neuroinflamm. 2016;3:e271.

62. Klein G, Delmar P, Voyle N, Rehal S, Hofmann C, Abi-Saab D, et al. Gantenerumab reduces amyloid-beta plaques in patients with prodromal to moderate Alzheimer's disease: a PET substudy interim analysis. Alzheimers Res Ther. 2019;11:101.

63. Ketter N, Brashear HR, Bogert J, Di J, Miaux Y, Gass A, Purcell DD, Barkhof F, Arrighi HM. Central review of amyloid-related imaging abnormalities in two phase III clinical trials of bapineuzumab in mild-to-moderate Alzheimer's disease patients. J Alzheimers Dis. 2017;57:557-73.

\section{Publisher's Note}

Springer Nature remains neutral with regard to jurisdictional claims in published maps and institutional affiliations.

Ready to submit your research? Choose BMC and benefit from:

- fast, convenient online submission

- thorough peer review by experienced researchers in your field

- rapid publication on acceptance

- support for research data, including large and complex data types

- gold Open Access which fosters wider collaboration and increased citations

- maximum visibility for your research: over $100 \mathrm{M}$ website views per year

At BMC, research is always in progress.

Learn more biomedcentral.com/submissions 